\title{
Genome-wide identification and characterization of the GDP-L-galactose phosphorylase gene family in bread wheat
}

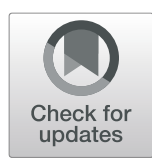

Ronan C. Broad ${ }^{1 \dagger}$, Julien P. Bonneau ${ }^{1 \dagger}$, Jesse T. Beasley ${ }^{1}$, Sally Roden², Joshua G. Philips², Ute Baumann², Roger P. Hellens ${ }^{2}$ and Alexander A. T. Johnson ${ }^{1 *}$ (D)

\begin{abstract}
Background: Ascorbate is a powerful antioxidant in plants and an essential micronutrient for humans. The GDP-Lgalactose phosphorylase (GGP) gene encodes the rate-limiting enzyme of the L-galactose pathway-the dominant ascorbate biosynthetic pathway in plants - and is a promising gene candidate for increasing ascorbate in crops. In addition to transcriptional regulation, GGP production is regulated at the translational level through an upstream open reading frame (UORF) in the long $5^{\prime}$-untranslated region ( $\left.5^{\prime} U T R\right)$. The GGP genes have yet to be identified in bread wheat (Triticum aestivum L.), one of the most important food grain sources for humans.

Results: Bread wheat chromosomal groups 4 and 5 were found to each contain three homoeologous TaGGP genes on the $A, B$, and D subgenomes (TaGGP2-A/B/D and TaGGP1-A/B/D, respectively) and a highly conserved uORF was present in the long $5^{\prime} U T R$ of all six genes. Phylogenetic analyses demonstrated that the TaGGP genes separate into two distinct groups and identified a duplication event of the GGP gene in the ancestor of the Brachypodium/ Triticeae lineage. A microsynteny analysis revealed that the TaGGP1 and TaGGP2 subchromosomal regions have no shared synteny suggesting that TaGGP2 may have been duplicated via a transposable element. The two groups of TaGGP genes have distinct expression patterns with the TaGGP1 homoeologs broadly expressed across different tissues and developmental stages and the TaGGP2 homoeologs highly expressed in anthers. Transient transformation of the TaGGP coding sequences in Nicotiana benthamiana leaf tissue increased ascorbate concentrations more than five-fold, confirming their functional role in ascorbate biosynthesis in planta.
\end{abstract}

Conclusions: We have identified six TaGGP genes in the bread wheat genome, each with a highly conserved uORF. Phylogenetic and microsynteny analyses highlight that a transposable element may have been responsible for the duplication and specialized expression of GGP2 in anthers in the Brachypodium/Triticeae lineage. Transient transformation of the TaGGP coding sequences in $\mathrm{N}$. benthamiana demonstrated their activity in planta. The six TaGGP genes and uORFs identified in this study provide a valuable genetic resource for increasing ascorbate concentrations in bread wheat.

Keywords: Ascorbic acid, Vitamin C, Upstream open reading frame, Phylogeny, Synteny, Gene expression, Transient expression

\footnotetext{
* Correspondence: johnsa@unimelb.edu.au

${ }^{+}$Ronan C. Broad and Julien P. Bonneau should be considered joint first author

${ }^{1}$ School of BioSciences, The University of Melbourne, Melbourne, Victoria

3010, Australia

Full list of author information is available at the end of the article
}

(c) The Author(s). 2019 Open Access This article is distributed under the terms of the Creative Commons Attribution 4.0 International License (http://creativecommons.org/licenses/by/4.0/), which permits unrestricted use, distribution, and reproduction in any medium, provided you give appropriate credit to the original author(s) and the source, provide a link to the Creative Commons license, and indicate if changes were made. The Creative Commons Public Domain Dedication waiver (http://creativecommons.org/publicdomain/zero/1.0/) applies to the data made available in this article, unless otherwise stated. 


\section{Background}

Ascorbate, also known as vitamin $\mathrm{C}$, is the most abundant water-soluble antioxidant in plant cells and plays important roles in photosynthetic function and stress tolerance [1, 2]. Ascorbate can mitigate the harmful effects of reactive oxygen species (ROS) produced by normal or stressed cellular metabolism, either directly as an ROS scavenger or indirectly as a substrate for the enzyme ascorbate peroxidase [3]. Increased biosynthesis of ascorbate in model and crop species has demonstrated that even minor increases in ascorbate can confer enhanced tolerance to a broad range of abiotic stresses $[4,5]$. Additional roles for ascorbate within plant cells include: serving as an enzymatic cofactor [6] and precursor for organic acids [7], as well as influencing the cell cycle [8], cell wall expansion [9], and flowering time and senescence [10].

In humans, ascorbate is an essential micronutrient due to loss-of-function mutations within the L-gulono-1,4lactone oxidase gene which encodes the enzyme responsible for catalysing the last step in vertebrate ascorbate biosynthesis [11]. Beyond its well-established role in preventing the disease scurvy, ascorbate plays key roles in many physiological processes important for human health, including promoting and regulating the uptake of dietary iron in the human digestive process [12] and serving as a cofactor for enzymes involved in epigenetic programming [5, 13]. Although ascorbate deficiency is considered a historical disease, suboptimal intake of ascorbate is currently present in both developing and developed countries [14], and the re-emergence of scurvy has been documented in Australia due to poor dietary habits [15].

Four pathways for ascorbate biosynthesis have been proposed in plants: the L-galactose, L-gulose, myo-inositol, and D-galacturonate pathways. Despite evidence for each of these pathways in plants, the L-galactose pathway, which converts D-fructose-6-P to ascorbate via eight enzymatic steps, is the dominant pathway leading to ascorbate biosynthesis in Arabidopsis thaliana [16-18], tomato (Solanum lycopersicum L.) [19], rice (Oryza sativa L.) [20], and green algae (Chlamydomonas reinhardtii) [21]. The final gene to be identified in the L-galactose pathway, GDP-L-galactose phosphorylase (GGP, also known as VTC2), was discovered and functionally characterized in Arabidopsis in 2007 [16, 22, 23]. The GGP enzyme catalyzes the conversion of GDP-L-galactose to L-galactose-1-P and represents the first committed step toward ascorbate biosynthesis. Several studies have now identified the GGP enzyme as the ratelimiting step in the L-galactose pathway [22, 24-26] and as the key regulatory enzyme in ascorbate biosynthesis [27]. Overexpression of GGP genes has increased ascorbate concentrations by up to 4.2-fold in Arabidopsis [24, 26], 3.1-fold in potato (Solanum tuberosum L.) [28], 2.1-fold in strawberry (Fragaria $x$ ananassa) [28], 6.2-fold in tomato
[28, 29], 1.4-fold in tobacco (Nicotiana tabacum L.) [30], and 2.6-fold in rice [25, 31].

A highly conserved upstream open reading frame (uORF) - a class of small ORFs located upstream of protein-coding major ORFs (mORFs) in the $5^{\prime}$-untranslated region (5'UTR) of mRNAs - of the GGP gene has been shown to regulate GGP translation and ascorbate concentrations [32-35]. Although uORFs are abundant in plant genomes with up to $60 \%$ of genes estimated to contain an UORF, less than $1 \%$ are conserved between plant species [36, 37]. The translational regulation of mORFs by highly conserved uORFs in response to cellular metabolite levels has been documented in several plant studies. For example, uORFs have been shown to regulate translation of the Arabidopsis S-adenosylmethionine decarboxylase and polyamine oxidase 2 genes in repsonse to polyamines [38-41], the Arabidopsis S1 class basic-leucine zipper and tomato ornithine decarboxylase genes in response to sucrose [42-44], the Arabidopsis phosphoethanolamine $N$-methyltransferase gene in response to phosphocholine [45], and the Arabidopsis heat shock trancription factor $B 1$ gene in response to galactinol [46]. In the case of the GGP uORF, the encoded peptide which is predicted to initiate from a non-canonical AUC or ACG start-codon is proposed to cause ribosomal stalling, thereby preventing translation of the downstream GGP mORF under high ascorbate concentrations, whereas under low ascorbate concentrations the UORF is skipped and the GGP mORF translated [33]. The precise mechanism of how ascorbate may influence ribosomal initiation at the UORF or mORF has yet to be elucidated. Disruption of the GGP uORF through mutation of key residues was shown to interfer with ascorbate feedback regulation of translation and increase ascorbate concentration when transiently transformed in Nicotiana benthamiana [33]. Recently, CRISPR/Cas9 genome editing has been used to disrupt the GGP uORF in Arabidopsis, lettuce (Lactuca sativa), and tomato to increase ascorbate concentrations and enhance oxidative stress tolerance [34, 35].

Despite the importance of the GGP gene in ascorbate biosynthesis and regulation, characterisation of GGP genes within graminaceous species has been limited to rice and maize (Zea mays L.). Both rice and maize have one copy of the GGP gene present in their genomes, located on chromosomes Os11 and Zm6, respectively. Complete knockout of the OsGGP gene in rice severely reduced foliar ascorbate concentrations by $80 \%$ and was correlated with reduced photosynthetic efficiency, lower biomass production, and reduced tolerance to ozone stress and zinc deficiency [20]. In maize, the ZmGGP gene is expressed during endosperm development and expression levels have been shown to be genotype-dependent [47].

Wheat is the world's most cultivated crop in terms of land area and accounts for one fifth of the calories 
consumed by humans [48]. Abiotic stresses such as drought, salinity, and high temperature represent the major limiting factors in global wheat productivity [49]. Increased ascorbate concentrations in wheat could help to mitigate yield losses associated with these abiotic stresses. Like many other cereals, wheat contains negligible levels of ascorbate in the mature grain [50], therefore, ascorbate enrichment of wheat grain could also provide a novel means of improving human dietary intakes of this essential vitamin.

Here we expand upon our knowledge of GGP genes in graminaceous species by describing the TaGGP gene family in bread wheat. We describe the chromosomal location, confirm the presence of the highly conserved uORFs, present phylogenetic relationship, gene synteny, and tissue and developmental expression patterns, and demonstrate activity of the TaGGP coding sequences by transient transformation in $N$. benthamiana.

\section{Results}

Six TaGGP genes were identified on bread wheat chromosomal groups 4 and 5

A total of six TaGGP genes were identified within the bread wheat genome and their genomic locations were determined. Chromosomal groups 4 and 5 each contain three homoeologous TaGGP genes located on the A, B, and D subgenomes (TaGGP2-A/TaGGP2-B/TaGGP2-D and TaGGP1-A/TaGGP1-B/TaGGP1-D, respectively). All six genes are located on the short arm of their respective chromosomal group except TaGGP2-A which is located on the long arm. In addition to the six TaGGP genes, we identified two HvGGP genes within the barley (Hordeum vulgare) genome on chromosomes 4 and 5 (HvGGP2 and $H v G G P 1$, respectively), two $B d G G P$ genes within the $B r a-$ chypodium distachyon (Brachypodium hereafter) genome on chromosome 4 (BdGGP1 and BdGGP2), two AetGGP genes within the Aegilops tauschii genome on chromosome 4 and 5 (AetGGP2 and AetGGP1, respectively), and one SbGGP gene within the Sorghum bicolor L. genome on chromosome 8.
The six TaGGP genomic sequences range in length from 2922 bp to 4163 bp mainly due to differences in intron sequence length (Fig. 1) and are similar in size and structure to other graminaceous GGP genes (Additional file 1: Figure S1). Genomic sequence comparisons of the six TaGGP genes revealed that they share between 36.0 to $94.9 \%$ identity. The TaGGP1 and TaGGP2 proteins are 430 and 431 amino acids in length, respectively, and sequence comparisons of the six TaGGP proteins revealed that they share between 78.1 to $99.3 \%$ identity. Alignment of the amino acid sequence of the wheat, barley, rice, maize, sorghum, Brachypodium, and A. tauschii GGP proteins identified highly conserved regions within the proteins, as well as the conserved histidine triad (HIT) motif of the HIT protein superfamily, the conserved KKRP nuclear localization signal (NLS), and 13 residues that distinguish GGP2 proteins from GGP1 proteins within these species (Fig. 2).

\section{Each TaGGP gene contains a highly conserved uORF}

For all six TaGGP genes, a highly conserved uORF was identified in the long 5'UTR of the mRNA initiating either from the non-canonical AUC (isoleucine) or ACG (threonine) start-codon. The uORF peptides of the TaGGP1 homoeologs and TaGGP2 homoeologs are 56 and 47 amino acids in length, respectively, and sequence comparisons of the six TaGGP uORF peptides revealed that they share between 67.9 to $100 \%$ identity. Alignment of the amino acid sequence of the GGP uORF peptides from a range of graminaceous and non-graminaceous species identified highly conserved regions within the peptides, as well as a lysine at the first residue in rice instead of a highly conserved isoleucine in all other species, a truncation of 11 residues in the TaGGP2, $H v G G P 2, B d G G P 2$, and AetGGP2 uORF peptides relative to the TaGGP1, HvGGP1, BdGGP1, and AetGGP1 uORF peptides, and a single amino acid change that distinguishes graminaceous species (alanine) from non-graminaceous species (glutamic acid) (Fig. 3).

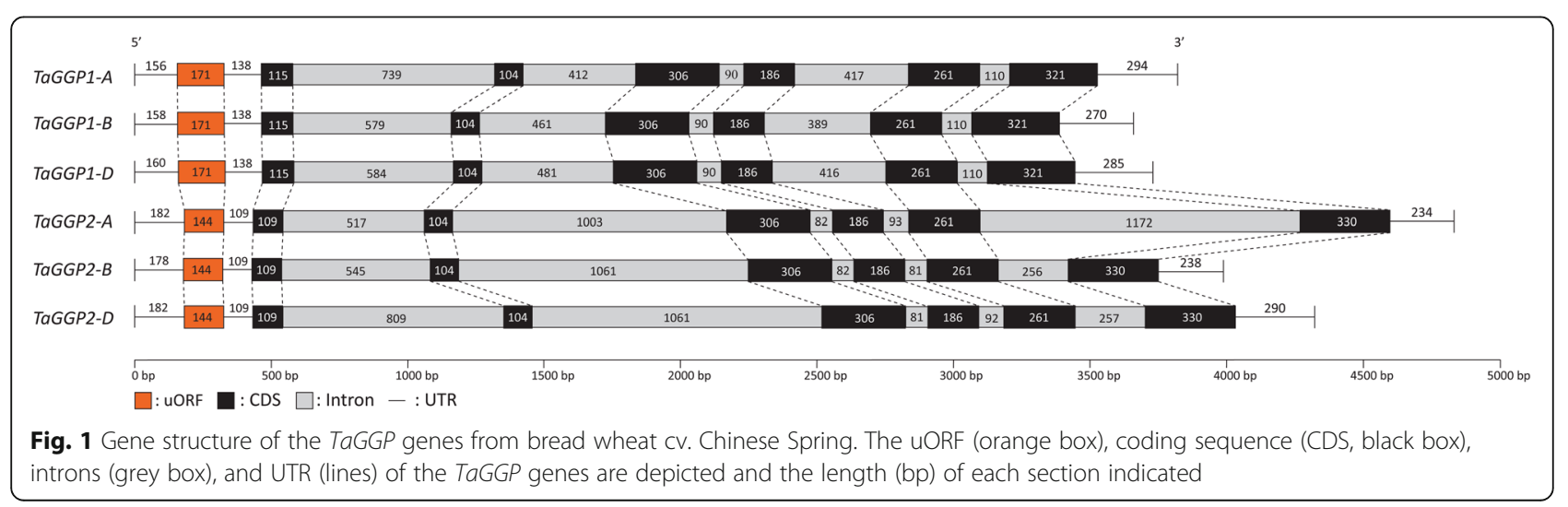




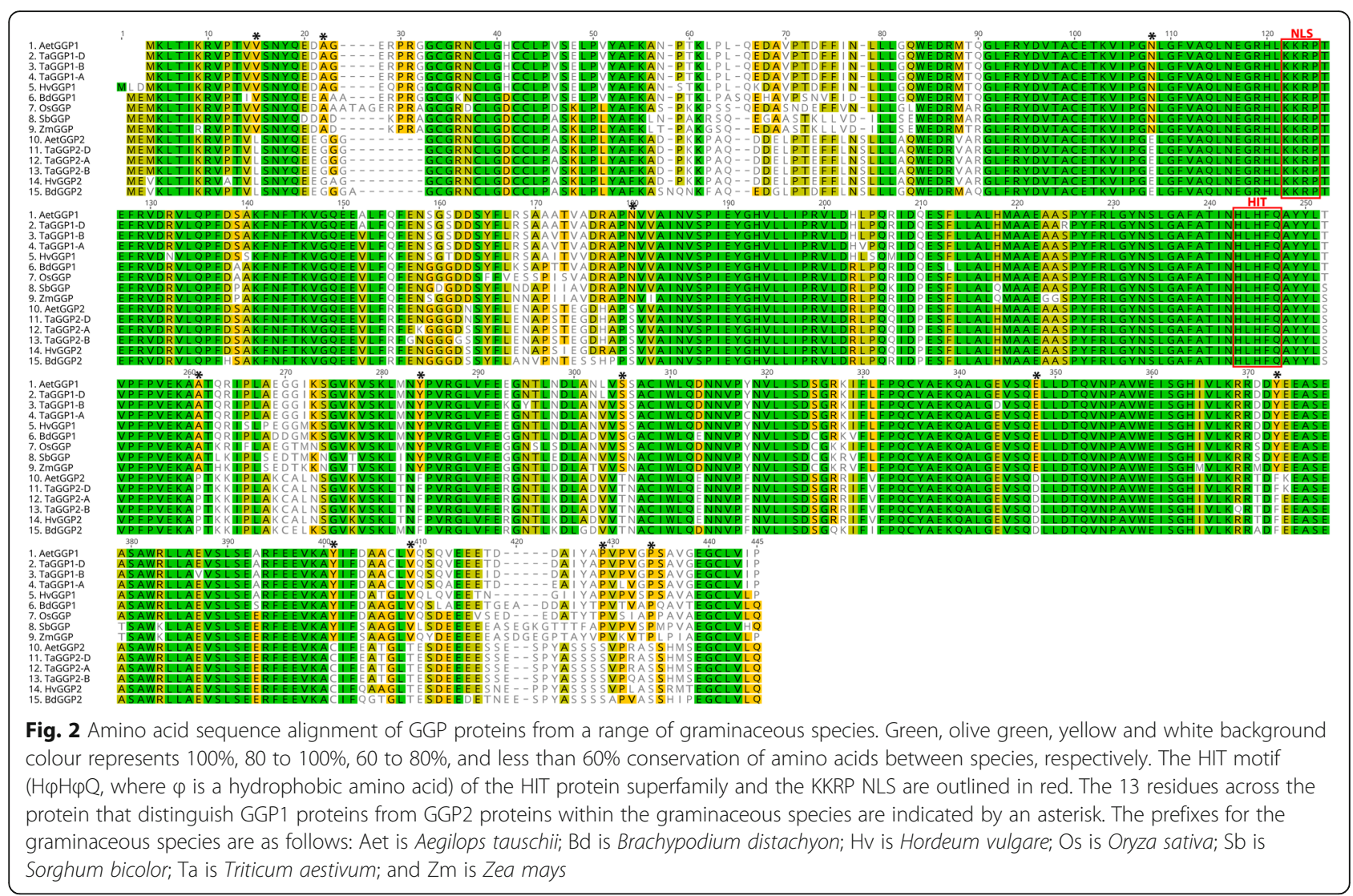

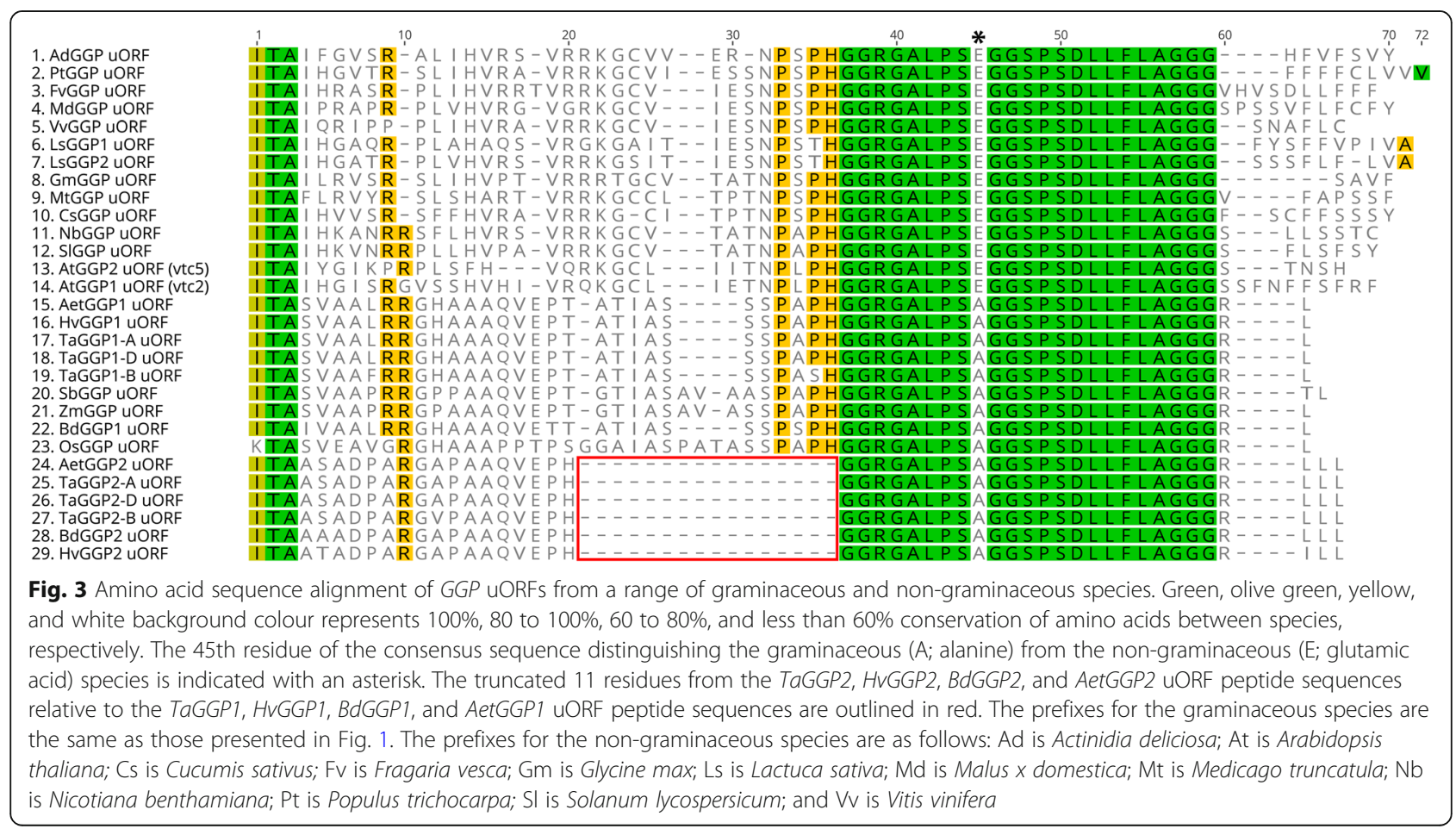


Graminaceous GGP proteins separate into two groups Phylogenetic analysis of the GGP protein sequences from a range of graminaceous and non-graminaceous plant species identified two clades of GGP proteins, belonging to either graminaceous or non-graminaceous species (Fig. 4). The graminaceous clade of GGP proteins further separates into two groups, with the TaGGP1 proteins forming one group with HvGGP1, BdGGP1, AetGGP1, OsGGP, ZmGGP, and SbGGP, and the TaGGP2 proteins forming a second group with HvGGP2, BdGGP2, and AetGGP2. This classification of group 1 and group 2 graminaceous GGP proteins is further supported by a phylogenetic analysis of the graminaceous GGP coding sequences which clearly demonstrates that the TaGGP1 homoeologs, $H v G G P 1, B d G G P 1$, and AetGGP1 are more closely related to the OsGGP, ZmGGP, and SbGGP in terms of evolutionary distance than the TaGGP2 homoeologs, HvGGP2, BdGGP2, and AetGGP2 (Additional file 1: Figure S2). Phylogenetic analysis of the GGP uORF peptide sequences revealed similar relationships to those observed for the GGP protein sequences (Additional file 1: Figure S3).

The TaGGP1 and TaGGP2 subchromosomal regions do not share synteny

Selection of ten genes upstream and downstream of the respective TaGGP genes on each of the six chromosomes, referred to as the TaGGP subchromosomal regions (SR), were analysed for gene density and synteny (Fig. 5 and Additional file 2: Table S1). The physical length of the TaGGP1-A, TaGGP1-B, and TaGGP1-D SRs were 18, 14.8 , and $8.7 \mathrm{Mbp}$, respectively, and the TaGGP2-A, TaGGP2-B, and TaGGP2-D SRs were 3.4, 4.8, and $3 \mathrm{Mbp}$, respectively. No shared synteny was found between the TaGGP1 and TaGGP2 SRs on chromosomal groups 4 and 5 except for the TaGGP genes themselves. Synteny between the TaGGP1 homoeologous SRs was much lower than that of the TaGGP2 homoeologous SRs with only 19 genes having shared synteny-the TaGGP1 homoeologs were the only genes to share synteny on all three homoeologous SRs-whereas the TaGGP2 homoeologous SRs have 37 genes with shared synteny. The TaGGP1 homoeologs are found in the centromeric region of their respective chromosomes, whereas the TaGGP2 homoeologs are found in the interstitial region of their respective chromosomes between the pericentromeric and telomeric regions.

\section{The two groups of TaGGP genes have distinct expression patterns in bread wheat tissues}

Quantitative reverse transcription-PCR analysis of a range of bread wheat tissues and developmental stages revealed distinct patterns of expression for the TaGGP1 and TaGGP2 genes (Fig. 6). The TaGGP1 homoeologs were

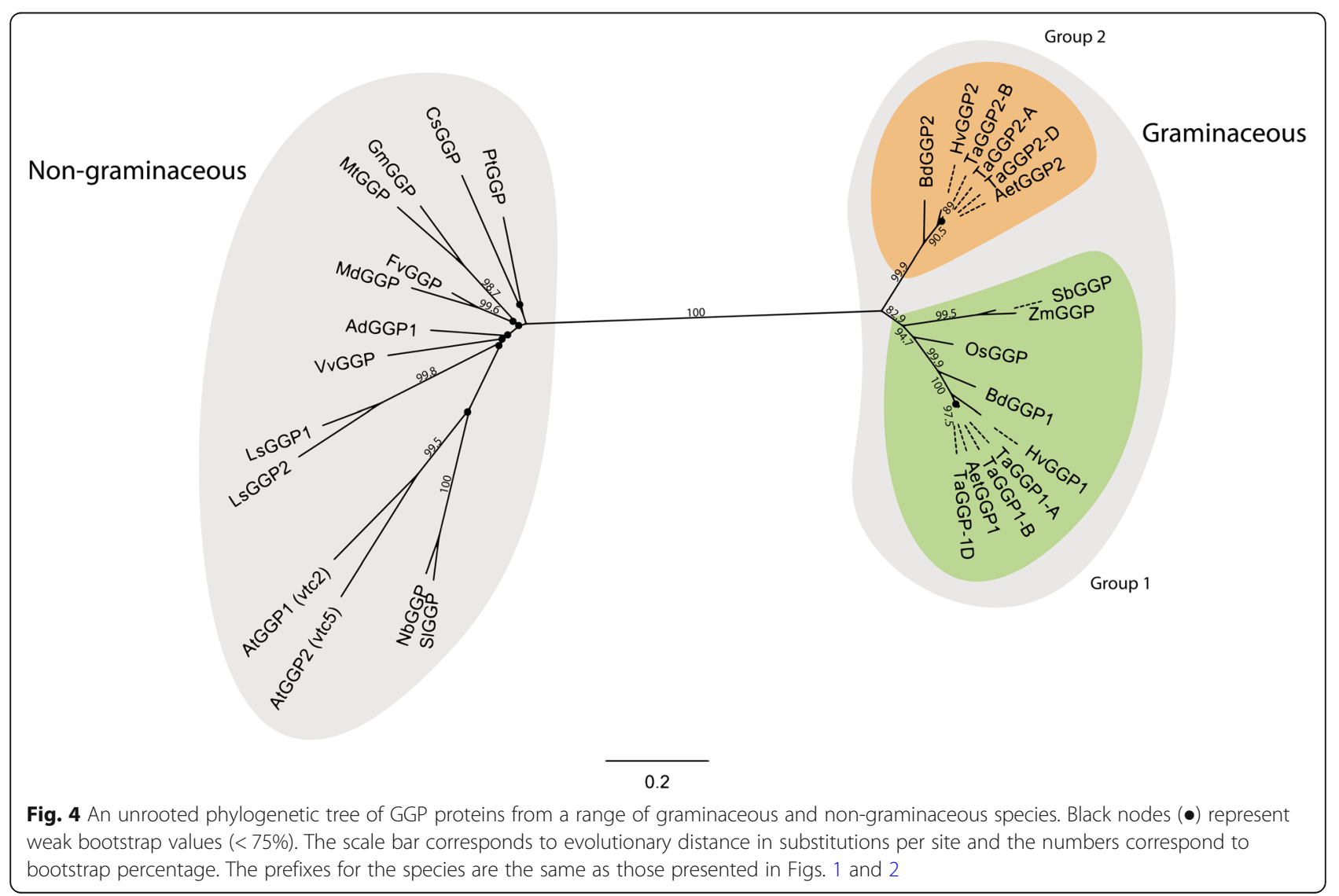




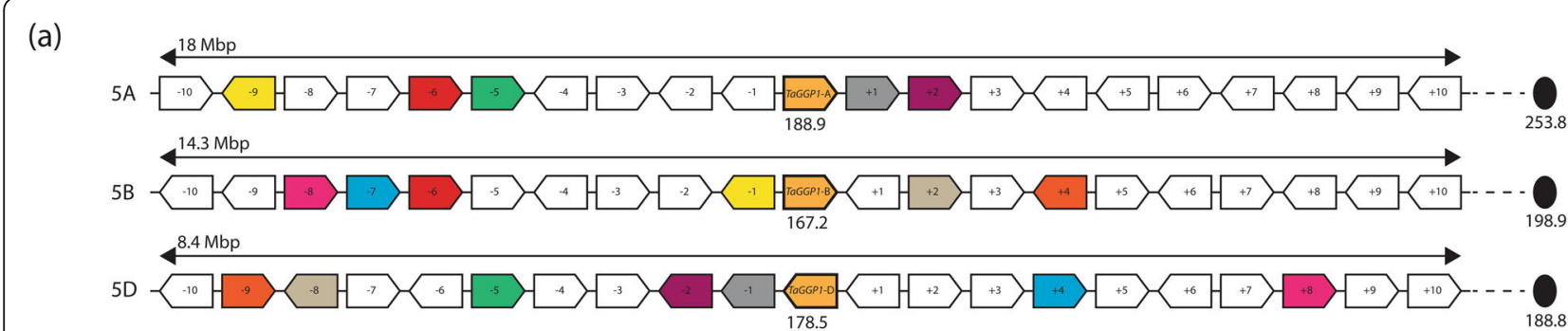

(b)

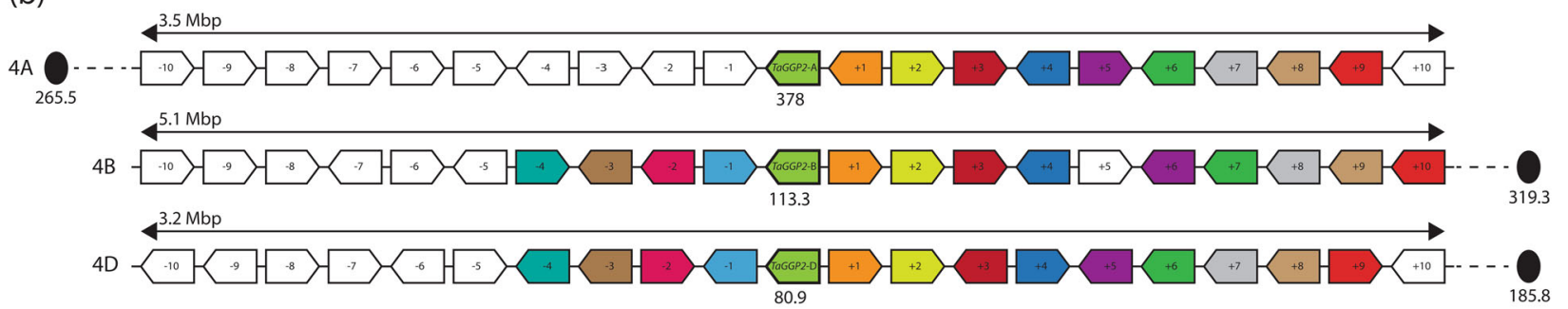

Fig. 5 Microsynteny analysis of the TaGGP genes from bread wheat cv. Chinese Spring. (a) TaGGP1 and (b) TaGGP2 homoeologous SRs on chromosomal groups 5 and 4, respectively. Syntenic genes are represented by arrow colour. The orientation of the genes is indicated by the direction of the arrows. The physical length (Mbp) of each of the TaGGP SRs is provided for each chromosome. The physical position (Mbp) of the TaGGP genes and the centromeres (black oval) are also presented. The physical distance (Mbp) between the proximal gene of the SR and the respective centromere (black dotted line) is 58.2, 22.2 and 4.4 for the TaGGP1-A, TaGGP1-B, and TaGGP1-D SRs, respectively, and 127.5, 203.8 and 104.6 for the TaGGP2-A, TaGGP2-B, and TaGGP2-D SRS, respectively. The list of genes used in this analysis and their respective position and gene function are provided in Additional file 2: Table S1

broadly expressed across different tissues and developmental stages, with the highest levels of expression detected in the seedling leaf, bracts, and anthers (Fig. 6a). The TaGGP1 homoeologs displayed a trend of nonbalanced expression with the TaGGP1-D homoeolog having lower expression levels across all tissues relative to TaGGP1-A and TaGGP1-B. In contrast to the TaGGP1 homoeologs, the TaGGP2 homoeologs were highly expressed in the anthers, with approximately 50- to 580fold higher expression in anthers relative to other tissues (Fig. 6b). The TaGGP2 homoeologs also displayed a trend of nonbalanced expression with the TaGGP2-B homoeolog having lower expression levels across all tissues relative to TaGGP2-A and TaGGP2-D. Taken together, the TaGGP genes were most highly expressed in anthers, seedling leaf, and bracts and most lowly expressed in the crown, seedling root, and caryopses 3-5 DAP.

We searched for anther/pollen specific cis-regulatory elements in the 1-kb promoter region of the TaGGP genes to identify whether the high expression of the TaGGP2 homoeologs in anthers could be explained due to differences in these regulatory elements (Additional file 1: Figure S4). However, the high level of expression of the TaGGP2 homoeologs in anthers does not appear to correlate with the density of anther/pollen cis-regulatory elements surrounding the transcription start site (TSS), with a higher density of anther/pollen cis-regulatory elements instead being present in regions surrounding the TSS of the TaGGP1 homoeologs (Additional file 1: Figure S4).
Transient transformation of TaGGP genes in $\mathrm{N}$. benthamiana leaf increases ascorbate concentration

Coding sequences of the TaGGP1-A, TaGGP1-B, TaGGP1-D, TaGGP2- $A$, and TaGGP2-B genes increased ascorbate concentrations in transiently transformed $N$. benthamiana leaf relative to the control (Fig. 7). Transformation with TaGGP1-D produced the greatest increase in ascorbate concentration (5.3-fold) relative to the control. Similar fold increases in ascorbate concentrations were also observed with transformation of TaGGP1-B (4.1-fold), TaGGP2-A (4.4-fold), and TaGGP2-B (4.5-fold). Transformation with TaGGP1-A produced a 2.4-fold increase relative to the control, which was the lowest increase in ascorbate concentration observed. Agrobacterium tumefaciens containing the TaGGP2-D construct were unable to be recovered. The higher fold increase in ascorbate observed for some of the TaGGP genes relative to the positive control AcGGP gene from kiwifruit may be explained by the strength of the promoters used to drive transgene expression: the dual $35 \mathrm{~S}$ promoter used to drive the TaGGP genes is a stronger promoter than the single $35 \mathrm{~S}$ promoter used to drive AcGGP.

\section{Discussion}

The TaGGP genes are highly conserved, functional, and have an uORF amenable to genome editing

We identified six TaGGP genes in the bread wheat genome, comprising of three TaGGP1 homoeologs on chromosomal group 5 and three TaGGP2 homoeologs on chromosomal 

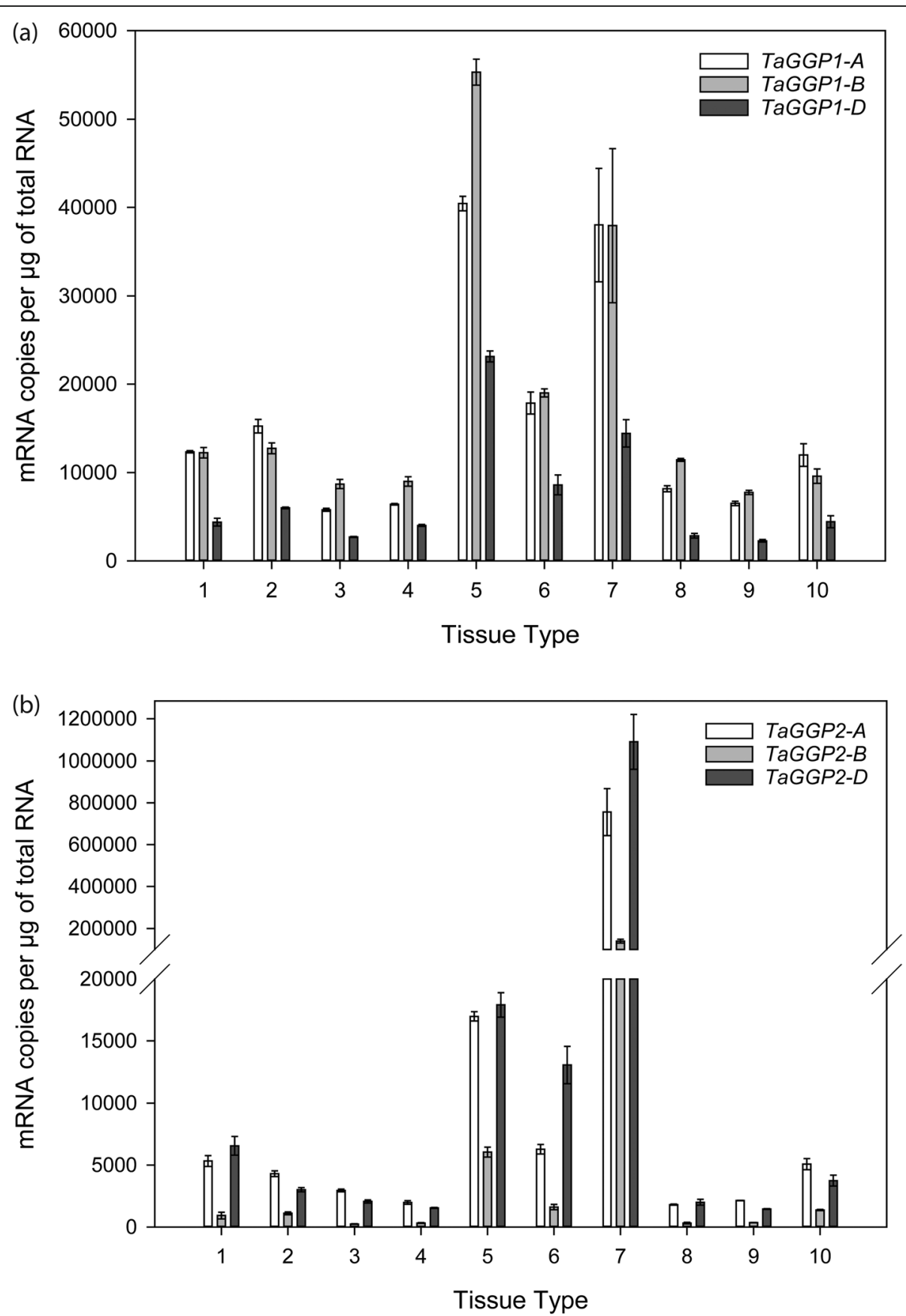

Fig. 6 Quantitative reverse transcription-PCR analysis of the TaGGP genes from bread wheat cv. Chinese Spring. Relative expression of the (a) TaGGP1 and (b) TaGGP2 homoeologs is provided in: (1) embryonic root; (2) mesocotyl; (3) seedling root; (4) crown; (5) seedling leaf; (6) bracts; (7) anthers; (8) pistil; (9) caryopsis 3-5 DAP; and (10) embryo 22 DAP. The geometric mean of TaActin, TaCyclophilin, and TaELF were used as normalisation factors. Error bars indicate SEM of three technical replicates derived from a bulk of three independent biological samples

group 4. Five of the genes are located on the short arm of their respective chromosomal group; the TaGGP2-A gene is located on the long arm of chromosome $4 \mathrm{~A}$ due to a known pericentric inversion between the long and short chromosome arms [51]. We have also identified two copies of the GGP gene in the barley, Brachypodium, and A. tauschii genomes, as well as one copy in the sorghum genome. To our knowledge, this is the first time that the HvGGP1, HvGGP2, BdGGP1, BdGGP2, AetGGP1, AetGGP2, and $S b G G P$ gene have been reported on.

The TaGGP protein sequences are highly conserved, particularly between homoeologs, with up to $99.3 \%$ shared 

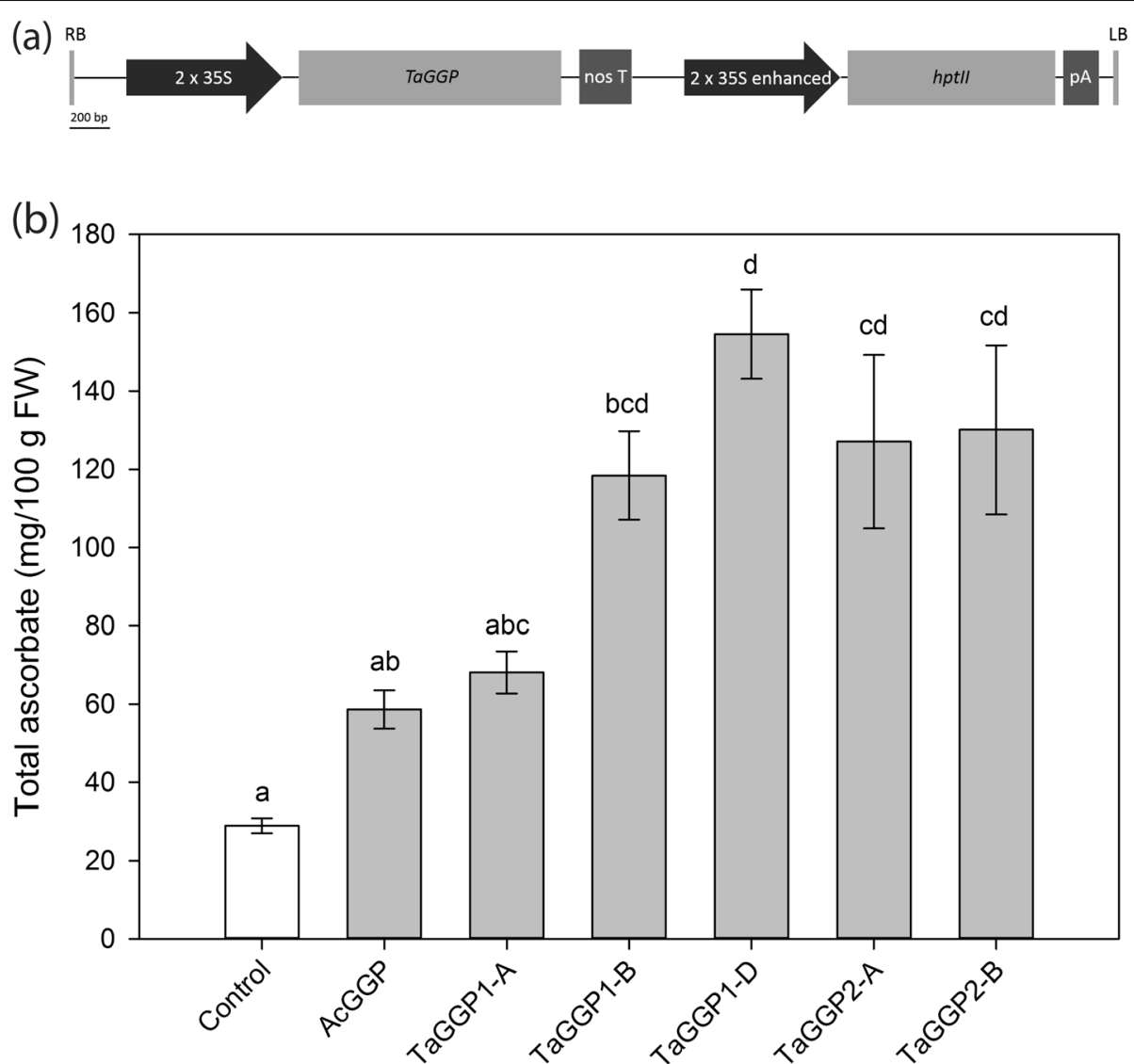

Fig. 7 Transient transformation of the TaGGP coding sequences in N. benthamiana. a Schematic representation of the T-DNAs used for constitutive overexpression of the TaGGP genes in N. benthamiana. RB, right border; $2 \times 35 \mathrm{~S}$, dual CaMV 355 promoter; TaGGP, coding sequence of TaGGP1-A (1,293 bp), TaGGP1-B (1,293 bp), TaGGP1-D (1,293 bp), TaGGP2-A (1,296 bp), and TaGGP2-B (1,296 bp); nos T, nopaline synthase terminator; 2 × $35 \mathrm{~S}$ enhanced, dual CaMV 35 S promoter enhanced; hptll, hygromycin phosphotransferase Il; PA, CaMV poly(A) signal; LB, left border. b Ascorbate concentrations of $\mathrm{N}$. benthamiana leaves co-infiltrated with A. tumefaciens (GV3101 MP90) containing the constructs of interest and a P19 construct to prevent post-transcriptional gene silencing. The control was infiltrated with A. tumefaciens containing the P19 construct alone. The AcGGP gene from kiwifruit driven by a single $35 \mathrm{~S}$ promoter in the pGreen vector system was used as a positive control. Bars represent mean \pm SEM of three infiltrated young leaves. Means that do not share a letter are significantly different (one-way ANOVA followed by Tukey post-hoc test with 95\% confidence level)

identity (Fig. 2). This high level of conservation is striking given the genetic redundancy of the hexaploid wheat genome, which generally displays accelerated rates of coding sequence evolution relative to diploid organisms such as Brachypodium and suggests that all six TaGGP genes play important functional roles during wheat development and as such may be resistant to genetic drift [52]. This hypothesis is consistent with our finding that all five TaGGP genes transiently transformed into $N$. benthamiana leaf increased leaf ascorbate concentrations relative to the control, confirming their functional role in ascorbate biosynthesis in planta (Fig. 7). We can also conclude from the transient transformation that the 13 residues that distinguish the graminaceous GGP2 proteins from GGP1 proteins do not appear to affect the function of the GGP2 proteins. The substantial increase in ascorbate concentrations in $N$. benthamiana leaf observed for the TaGGP genes is consistent with GGP as the rate-limiting step towards ascorbate biosynthesis in plants [22, 24-26], and demonstrates the potential of utilising these genes, particularly TaGGP1-D, to increase ascorbate concentrations not only in wheat but other crops.

All six TaGGP proteins contained the highly conserved $\mathrm{H} \phi \mathrm{H} \phi \mathrm{Q}$ motif (where $\phi$ is a hydrophobic amino acid) that is characteristic of the galactose-1-phosphate uridylyltransferase branch of the HIT superfamily (Fig. 2.) $[22,23,53]$. They also all possess the highly conserved KKRP NLS, which may be responsible for localizing the TaGGP proteins to the nucleus, in addition to the cytoplasm where most of the ascorbate biosynthesis occurs (Fig. 2.) [54]. Fusion proteins of AtGGP1:YFP, SlGGP1-GFP, and SlGGP2:GFP have been found to localize to the cytoplasm and nucleus suggesting that GGP may be a dual-function protein serving both enzymatic and regulatory roles [54-56]. Determining the extent to which this NLS influences subcellular localization of 
GGP and what role GGP may be playing in the nucleus warrants further investigation.

We also identified a highly conserved uORF in the long 5'UTR of the mRNA for each of the six TaGGP genes (Figs. 1 and 3). Notably, the uORF of the TaGGP2 homoeologs had a truncation of 11 residues relative to the TaGGP1 homoeologs and the same truncation of 11 residues was also observed for the $B d G G P 2$ and $H v G G P 2$ uORFs relative to the $B d G G P 1$ and HvGGP2 uORFs, respectively, indicating that this truncation occurred prior to the evolutionary divergence of Brachypodium and the Triticeae tribe (Fig. 3). If theses graminaceous GGP2 uORFs are still functional this would suggest that these 11 residues are not critical to the functionality of the peptide. Disruption of the GGP uORF through genome editing has recently been shown as a viable strategy to increase ascorbate concentrations in a variety of plant species [34, 35]. For example, CRISPR/Cas9-targeted mutagenesis of the AtGGP1 uORF in Arabidopsis and the LsGGP1 and LsGGP2 uORFs in lettuce to disrupt their function increased foliar ascorbate concentrations 1.7-, 1.4-, and 2.6fold, respectively. Additionally, the increased ascorbate concentrations in lettuce conferred enhanced tolerance to methyl viologen-induced oxidative stress [35]. Similarly, CRISPR/Cas9-targeted mutagenesis of the SlGGP2 uORF in tomato to disrupt its function increased foliar ascorbate concentrations approximately 1.4-fold [34]. Due to the plasticity of the hexaploid wheat genome, manipulating individual or multiple TaGGP uORFs with genome editing tools such as CRISPR/Cas9 represents a promising strategy to produce ascorbate-enriched wheat plants whilst also minimizing any pleiotropic effects on plant development that may arise due to disruption of the GGP uORF.

\section{A Mutator-like transposable element may be responsible for the duplication and specialized gene expression of GGP2 in the Brachypodium/Triticeae lineage}

We have categorized the graminaceous GGP genes described in this manuscript as group 1 or group 2 based on phylogeny. The protein and coding sequences of the TaGGP1 homoeologs, AetGGP1, HvGGP1, and BdGGP1 are more closely related to OsGGP, ZmGGP, and SbGGP in terms of evolutionary distance than that of the TaGGP2 homoeologs, AetGGP2, HvGGP2, and BdGGP2 (Fig. 4.). This grouping of graminaceous GGP1 and GGP2 genes is also consistent with the chromosomal location of the GGP genes and the known evolutionary history of grass genomes. For example, the wheat chromosomal group Ta5, barley chromosome Hv5, Brachypodium chromosome Bd4, rice chromosome Os12, and sorghum chromosome Sb8, which each harbour GGP1 genes, are all descended from the ancestral grass chromosome A12 [57]. Whereas, the wheat chromosomal group Ta4, barley chromosome Hv4, and Brachypodium chromosome Bd4, which each harbour GGP2 genes, are all descended from the ancestral grass chromosome A11 (in Brachypodium A11 and A12 were fused to form the single chromosome Bd4) [57]. Given that rice, maize, and sorghum each have a single copy of GGP, while wheat, barley, Brachypodium, and $A$. tauschii each have two copies of GGP, it appears that GGP may have been duplicated from A12 to A11 in the ancestor of the Brachypodium/Triticeae lineage. This duplication event would have occurred after the evolutionary divergence of the Brachypodium/Triticeae lineage from rice approximately 33.5 million years ago (MYA) but prior to the evolutionary divergence of Brachypodium and the Triticeae tribe approximately 24.5 MYA [57].

Our microsynteny analysis of the TaGGP genes revealed that the TaGGP1 and TaGGP2 SRs have no shared synteny except for the TaGGP genes themselves (Fig. 5.). We also did not find any shared synteny between the BdGGP1 and BdGGP2 SRs in Brachypodium (Additional file 2: Table S2) or between the HvGGP1 and $H v G G P 2$ SRs in barley (Additional file 2: Table S3). This lack of synteny between the GGP1 and GGP2 SRs in wheat, Brachypodium, and barley suggests that GGP2 may have been duplicated via transposition in the ancestor of the Brachypodium/Triticeae lineage since other methods of gene duplication preserve gene synteny [58]. Given that the introns and gene structure of the wheat, Brachypodium, and barley GGP2 genes have been preserved, a Class II transposable element (DNA transposon) that transposes via a DNA intermediate may have been responsible for such a transposition. We propose that a Mutator-like transposable element (MULE) - a family of DNA transposons that are prevalent in plants and capable of capturing, mobilizing, and amplifying gene fragmentsmay have been responsible for the duplication of GGP2 [59]. However, given the proposed evolutionary time since GGP2 was duplicated (24.5 to 33.5 MYA) any features of the transposable element would have degenerated by now and no longer be detectable [58].

We identified distinct expression patterns for the TaGGP1 and TaGGP2 genes with the TaGGP1 homoeologs broadly expressed across different tissues and developmental stages, whereas the TaGGP2 homoeologs were highly specialized with approximately 50 - to 580 -fold higher expression in anthers relative to other tissues (Fig. 6.). Our TaGGP gene expression results are supported by gene expression data extracted from http://bar.utoronto. ca/ which also demonstrates that the TaGGP1 homoeologs are broadly expressed across different tissues and development stages, and that the TaGGP2 homoeologs are highly expressed in anthers and leaves relative to other tissues (Additional file 1: Figure S5). Similar GGP expression profiles were also observed for other graminaceous species in terms of higher expression in anthers and/or leaves relative to other tissues (Additional file 1: Figures S5 and S6). To 
our knowledge this is the first time that specialized expression of a GGP gene in anthers has been documented, however, a previous study found high ascorbate concentrations correlated with high RNA concentrations in the developing anthers of jimsonweed (Datura stramonium L.) [60]. Together this expression data suggests that ascorbate may play an important role in anther development in wheat and other graminaceous species, for example protecting pollen from ROS induced by environmental stresses [61]. Determining whether the high expression of GGP in anthers is correlated with higher ascorbate concentrations relative to other tissues warrants further study.

In regards to the origin of the cis-regulatory elements responsible for the high expression of GGP2 genes in the anthers relative to other tissues in wheat, Brachypodium, and barley, we propose two hypotheses: (i) following duplication, the regulatory region of the GGP2 gene diverged due to a reduction in selection pressure, which subsequently generated de novo cis-regulatory elements, or (ii) cis-regulatory elements in the regulatory region were inherited from a transposable element that may have been responsible for the duplication of GGP2. In support of the first hypothesis, sequence alignments of the 1-kb promoter region of the wheat, Brachypodium, and barley GGP genes demonstrate that the promoter region of the GGP2 genes have commonalities with the promoter region of the GGP1 genes but have otherwise diverged significantly (Additional file 1: Figure S7). It is possible that sequence changes to the promoter region of GGP2 genes have generated de novo cis-regulatory elements responsible for the high expression of GGP2 genes in anthers. On the other hand, transposable elements are known to influence the expression of transposed genes [58]. For example, MULEs-including any sequences that have been captured, mobilized, and amplified by a MULE-have been shown to be preferentially expressed in reproductive tissues [58, 62]. The terminal inverted repeat (TIR) of MULEs are proposed to serve as the regulatory region for the expression of MULEs, including any transposed gene fragments $[58,62]$. If GGP2 was transposed by a MULE in the ancestor of the Brachypodium/ Triticeae lineage, it is possible that GGP2 inherited cisregulatory elements responsible for the high expression of GGP2 in anthers directly from the TIR of the MULE.

\section{Applications towards plant breeding}

Abiotic stresses, such as high temperature, are responsible for major losses in global wheat productivity and are predicted to intensify due to climate change [63]. Identifying genetic strategies to mitigate or offset these losses will be essential for maintaining global wheat production levels. Exogenous application of ascorbate to wheat plants has been shown to alleviate salt- and drought-induced oxidative stress in many studies [64-69]. The development of high-ascorbate bread wheat cultivars through overexpression of the TaGGP genes or genome editing of one or more TaGGP uORFs to disrupt their function could help to mitigate wheat production losses caused by abiotic stress without the need for exogenous applications.

With respect to human nutrition, the development of bread wheat products with elevated levels of ascorbate may be limited due to the decline of ascorbate to negligible levels during grain maturation that may be difficult to overcome [70, 71]. However, wheat products made from germinated grain may provide a vehicle for ascorbate biofortification since germinated grain contains considerably higher levels of ascorbate relative to nongerminated grain [72, 73]. Germinated grain from bread wheat cultivars with an enhanced capacity to biosynthesize ascorbate could represent a novel way for improving human dietary intake of ascorbate.

\section{Conclusions}

We identified six TaGGP genes in the bread wheat genome, each with a highly conserved uORF. Phylogenetic and microsynteny analyses revealed that GGP2 may have been duplicated via a transposable element in the ancestor of the Brachypodium/Triticeae lineage. The TaGGP2 homoeologs had specialized expression in anthers which may have been inherited from the TIR of a MULE. Transient transformation of the TaGGP coding sequences in $N$. benthamiana leaf increased ascorbate concentrations up 5.3-fold, confirming their activity in planta. We propose that the six TaGGP genes and uORFs identified in this study will provide a valuable genetic resource for increasing ascorbate biosynthesis in bread wheat to improve wheat abiotic stress tolerance and human nutrition.

\section{Methods}

Identification and naming of the GGP genes and uORFs The OsGGP coding sequence (LOC4351698) was used as a query in BLASTN searches against the International Wheat Genome Sequencing Consortium (IWGSC) RefSeq v1.0 assembly of the wheat genome cv. Chinese Spring [48] to identify TaGGP coding sequences. Each TaGGP gene was assigned a unique name based on homoeologous grouping and their respective subgenomes and followed the recommended rules for gene symbolization in wheat (http:// wheat.pw.usda.gov/ggpages/wgc/98/Intro.htm). Gene prediction models including predicted coding and proteins sequences were obtained from the IWGSC database. The OsGGP coding sequence was also used as a query in BLASTN searches against the genome sequence databases for barley (IBSC_v2), Brachypodium (Brachypodium_distachyon_v3.0), A. tauschii (Aet_v4.0) from https://plants. ensembl.org and for sorghum (Sorghum_bicolor_NCBIv3) from https://www.ncbi.nlm.nih.gov. The structure of the GGP genes was determined with Splign (https://www.ncbi. 
nlm.nih.gov/sutils/splign/splign.cgi) [74]. The GGP uORF coding and peptide sequences were manually identified in the 5'UTR of the GGP genes starting from the highly conserved AUC codon encoding isoleucine as previously described [33].

\section{Cloning and gene sequencing}

Full-length gene sequences of TaGGP1-A and TaGGP2-A could not be retrieved from the IWGSC RefSeq v1.0 assembly of the wheat genome cv. Chinese Spring [48] due to each gene having a gap in intron 2 where sequence was missing. PCR primers were designed to amplify gene fragments spanning the gap of the TaGGP1-A and TaGGP2-A genes from cv. Chinese Spring genomic DNA using the respective IWGSC gene sequences and Primer3 software $[75,76]$. The TaGGP1 gene fragment was PCR amplified with forward primer 5' - GGCAATCTGTTAGGCAAGCA $-3^{\prime}$ and reverse primer $5^{\prime}$ - TGTCAAAAACAGGTATCA GCAATTT - 3'. The TaGGP2 gene fragment was PCR amplified with forward primer $5^{\prime}$ - AGTTCTTCCTAAAT TCTCTCCTCCTT - $3^{\prime}$ and reverse primer $5^{\prime}$ - TTGAGG AATCACCTCACCCTA - 3'. PCR amplification cycles consisted of 1 cycle $=1 \mathrm{~m} 95^{\circ} \mathrm{C} ; 35$ cycles $=20 \mathrm{~s} 95^{\circ} \mathrm{C}, 30 \mathrm{~s}$ $61{ }^{\circ} \mathrm{C}, 30 \mathrm{~s} 72{ }^{\circ} \mathrm{C} ; 1 \mathrm{cycle}=5 \mathrm{~m} 72{ }^{\circ} \mathrm{C}$. PCRs were performed in a final volume of $20 \mu \mathrm{L}$ for MyTaq ${ }^{\text {Tw }}$ HS Red DNA Polymerase (Bioline, MA, USA) according to manufacturer's instructions. The PCR products were purified with DNA Clean \& Concentrator-5 (Zymo Research, CA, USA) and cloned into the pGEM ${ }^{\circ}$ T Vector System (Promega, WI, USA) according to manufacturer's instructions. Restriction enzyme digestion of the cloned PCR products in PGEM $^{\circ}-\mathrm{T}$ with PvuII (New England Biolabs, MA, USA) according to the manufacturer instructions was used to discriminate the TaGGP1- $A$ and TaGGP2-A gene fragments from their respective $\mathrm{B}$ and $\mathrm{D}$ homoeologous gene fragments prior to Sanger sequencing at the Australian Genome Research Facility Ltd. (http://www.agrf.org.au/).

\section{Sequence alignment and phylogenetic analysis of the GGP and uORF sequences}

Sequence alignment and phylogenetic analysis of the GGP coding, protein, and uORF peptide sequences were performed in Geneious 10.2.2 using ClustalW alignment with default parameters and the PhyML Geneious plugin [77] with a K80 substitution model for nucleotide sequences or a LG substitution model for amino acid sequences and a bootstrap value of 1000. The GGP genes used in the sequence alignments and phylogenetic analyses are provided in Additional file 2: Table S4.

\section{Microsynteny analysis of the TaGGP, BdGGP, and HvGGP genes}

Ten high confidence genes upstream and downstream of the six TaGGP, two BdGGP, and two HvGGP genes were retrieved from the IWGSC RefSeq v1.0 assembly of the wheat genome cv. Chinese Spring [48], the Brachypodium_distachyon_v3.0 assembly of the Brachypodium genome (https://plants.ensembl.org), and the IBSC_v2 assembly of the barley genome (https://plants.ensembl. org), respectively, excluding genes associated with retrotransposons and retrovirus related polyproteins, and used as query sequences in BLASTN searches against the respective databases with an E-value threshold of $1 \mathrm{e}^{-10}$. The genes were considered syntenic based on their genomic location and sequence identity $(\geq 90 \%)$. The list of the genes used in the microsynteny analysis of the six TaGGP, two BdGGP, and two HvGGP genes, and their respective position and gene function, are provided in Additional file 2: Tables S1, S2, and S3, respectively.

\section{Quantitative reverse transcription-PCR analysis of the TaGGP genes}

The cDNA library of 10 different tissues and development stages of bread wheat cv. Chinese Spring was previously generated as described [78]. The quantitative reverse transcription-PCR analysis of the six TaGGP genes was carried out using subgenome specific PCR primer pairs (Additional file 2: Table S5) for each TaGGP gene as previously described [79]. Subgenome specificity of primer pairs was verified using cv. Chinese Spring nulli-tetrasomic DNA [80]. Primer efficiency was $\geq 97 \%$ for all primer pairs. A three gene normalisation factor of the most stable housekeeping genes TaActin, TaCyclophilin, and TaELF was used to normalise qRTPCR expression data as previously described [78, 81]. Supplementary GGP gene expression data was extracted using the corresponding gene identifiers provided in Additional file 2: Table S4 from http://bar.utoronto.ca/ for wheat [82], barley [83], and maize [84], and from https://www.ebi.ac.uk for Brachypodium, rice, and sorghum [85].

\section{Analysis of TaGGP promoter regions}

For each TaGGP gene, the first exon as well as the 1-kb upstream region, which was considered the promoter region, was extracted from the genome sequence databases for T. aestivum (IWGSC) from https://plants.ensembl. org. These sequences were used as a query in BLASTN searches against the NCBI expressed sequence tag (EST) database for T. aestivum (https://blast.ncbi.nlm.nih.gov) to identify TaGGP cap-trapped full-length cDNA sequences and the TTS. The identification of anther/ pollen cis-acting elements was performed in Geneious 10.2.2 as previously described [79]. Sequence alignment of the 1-kb promoter region of the GGP genes was performed in Geneious 10.2.2 using the MAFFT Geneious plugin [86] with a L-INS-i algorithm. 


\section{Transient transformation of $\boldsymbol{N}$. benthamiana leaves}

Bread wheat cv. Gladius was sourced from the Australian Grains Genebank (https://www.seedpartnership.org.au/associates/agg). PCR primers were designed to amplify the coding sequence of the TaGGP1 homoeologs and TaGGP2 homoeologs from bread wheat cv. Gladius cDNA using Primer3 software [75, 76]. The TaGGP1 homoeologs were PCR amplified with forward primer 5' - ATGAAGCTGA CGATTAAGAGGGTA $-3^{\prime}$ and reverse primer $5^{\prime}-$ TCACGGAATTACGAGGCAG - $3^{\prime}$. The TaGGP2 homoeologs were PCR amplified with forward primer $5^{\prime}$ - ATGGAGATGAAGCTGACGAT - $3^{\prime}$ and reverse primer $5^{\prime}$ TCACTGAAGGACAAGGCAAC - 3'. PCR amplification cycles consisted of 1 cycle $=30 \mathrm{~s} \quad 98^{\circ} \mathrm{C} ; 35$ cycles $=10 \mathrm{~s}$ $98^{\circ} \mathrm{C}, 15 \mathrm{~s} 61{ }^{\circ} \mathrm{C}, 45 \mathrm{~s} 72{ }^{\circ} \mathrm{C} ; 1$ cycle $=5 \mathrm{~m} 72{ }^{\circ} \mathrm{C}$. PCRs were performed in a final volume of $50 \mu \mathrm{L}$ for Phusion HighFidelity DNA Polymerase (New England Biolabs) according to the manufacturer's instructions. The PCR products were purified with DNA Clean \& Concentrator-5 (Zymo Research), A overhangs added with MyTaq ${ }^{\text {Tm }}$ HS DNA Polymerase (Bioline), ligated into the $\mathrm{pCR} 8 / \mathrm{GW} / \mathrm{TOPO}$ vector system using the $\mathrm{pCR}^{\mathrm{m}} 8 / \mathrm{GW} / \mathrm{TOPO}^{\circ} \mathrm{TA}$ Cloning Kit (Invitrogen, CA, USA), and recombined into the pMDC32 vector system [87] using Gateway ${ }^{\mathrm{mm}}$ LR Clonase ${ }^{\mathrm{Tw}}$ II Enzyme mix (Invitrogen) according to the manufacturer's instructions. Cloning of the correct gene family member and gene orientation was confirmed by Sanger sequencing at the Australian Genome Research Facility Ltd. A. tumefaciens (GV3101 pMP90) containing the constructs of interest (except TaGGP2-D) were co-infiltrated with $A$. tumefaciens containing a P19 construct [88] to prevent posttranscriptional gene silencing into the younger leaves of 6week-old $N$. benthamiana plants (LAB strain) grown in a plant growth room $\left(16 \mathrm{~h}\right.$ daylength, $\left.24^{\circ} \mathrm{C}\right)$ [89]. Infiltration conditions were conducted as previously described [90]. Infiltration with $A$. tumefaciens containing the P19 construct alone was used as a control. Infiltration with $A$. tumefaciens containing the kiwifruit $A c G G P$ gene in the pGreen vector system [24, 91] was used as a positive control. Leaves were harvested for ascorbate measurements $7 \mathrm{~d}$ after infiltration and frozen on dry ice.

\section{Ascorbate measurement}

Total ascorbate was extracted and measured as previously described with modifications [92]. Briefly, total ascorbate was extracted from ground, lyophilized tissue homogenised in extraction fluid containing $8 \%$ metaphosphoric acid, $2 \mathrm{mM}$ EDTA, and $2 \mathrm{mM}$ TCEP (SigmaAldrich, MO, USA) at $40^{\circ} \mathrm{C}$ for $2 \mathrm{~h}$. The extract was centrifuged and $5 \mu \mathrm{l}$ of supernatant was injected onto a C18 $3 \mu \mathrm{m} 33 \times 7 \mathrm{~mm}$ Alltima Rocket column (Hichrom Limited, UK) with a flow rate of $1 \mathrm{~mL} / \mathrm{m}$. The concentration was determined by reverse phase HPLC with UV detection at $245 \mathrm{~nm}$ on a Shimadzu (Japan) 8050 instrument
(RT $1.43 \mathrm{~m}$ ) using ascorbic acid as a standard (Sigma-Aldrich). The elution procedure was gradient with mobile phases A: MS grade water with 1\% formic acid (Sigma-Aldrich) and B: MS grade acetonitrile with $1 \%$ formic acid (Sigma-Aldrich). The peak was validated as ascorbic acid by using L-ascorbic acid analytical standard (Sigma-Aldrich) with HPLC-MS Multi Reaction Monitoring (MRM) scan, qualifier transition $\mathrm{m} / \mathrm{z}(+)=177.05>95.00$.

\section{Statistical analysis}

Statistically significant differences between means were detected using a one-way ANOVA followed by a Tukey post-hoc test with a $95 \%$ confidence level using Minitab ${ }^{\circ}$ 17.1.0 (http://www.minitab.com/en-us/).

\section{Supplementary information}

Supplementary information accompanies this paper at https://doi.org/10. 1186/s12870-019-2123-1.

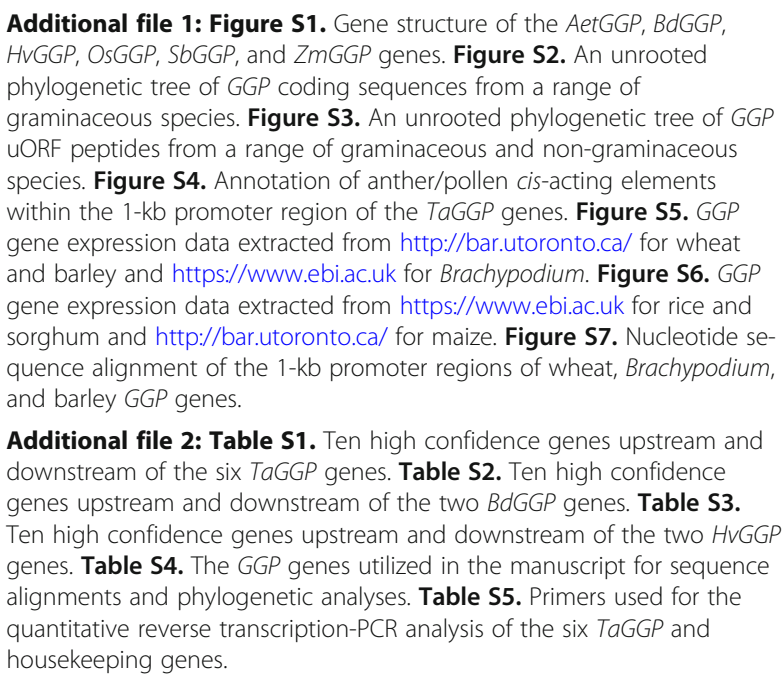

Additional file 2: Table S1. Ten high confidence genes upstream and downstream of the six TaGGP genes. Table S2. Ten high confidence genes upstream and downstream of the two BdGGP genes. Table S3. Ten high confidence genes upstream and downstream of the two HVGGP genes. Table S4. The GGP genes utilized in the manuscript for sequence alignments and phylogenetic analyses. Table S5. Primers used for the quantitative reverse transcription-PCR analysis of the six TaGGP and housekeeping genes.

\section{Abbreviations}

5'UTR: 5' untranslated region; EST: Expressed sequence tag; GGP: GDP-Lgalactose phosphorylase; HIT: Histidine triad; mORF: Major open reading frame; MULE: Mutator-like transposable element; NLS: Nuclear localization signal; ROS: Reactive oxygen species; SR: Subchromosomal regions; TIR: Terminal inverted repeat; TSS: Transcription start site; UORF: Upstream open reading frame

\section{Acknowledgements}

The authors would like to thank Margaret Pallotta for providing wheat CV. Chinese Spring nulli-tetrasomic DNA used in this study.

\section{Author's contributions}

JPB, RPH, AATJ conceived and designed the research. JPB identified the GGP genes and UORFs and RCB visualized their structures. RCB and JTB conducted the phylogenetic analyses. JPB and UB conducted the microsynteny analysis. JTB confirmed the specificity of the subgenome primers for the quantitative reverse transcription-PCR analysis and analysed the data. JPB analysed the supplementary gene expression data. JPB, RCB, and UB analysed the promoter regions. RCB, SR, and JGP conducted the transient transformation of $N$. benthamiana and quantified the ascorbate concentrations. JPB, RPH, and AATJ supervised the research. RCB drafted the manuscript. All authors read and approved the manuscript. 


\section{Funding}

No funding was obtained for this study.

\section{Availability of data and materials}

The GGP and UORF sequences, as well as the supplementary gene expression data, analysed during this study are available from public databases as outlined in the material and methods and supplementary material. The GenBank accession numbers for the bread wheat cv. Gladius TaGGP coding sequences generated during the current study are: TaGGP1-A, MK514258; TaGGP1-B, MK514259; TaGGP1-D, MK514260; TaGGP2-A, MK514261; TaGGP2-B, MK514262; and TaGGP2-D, MK514263. The GenBank accession numbers will be searchable after Feb 13, 2020 or once the accession numbers appear in print. The remaining datasets generated during the current study are available from the corresponding author on reasonable request.

\section{Ethics approval and consent to participate}

Not applicable.

\section{Consent for publication}

Not applicable.

\section{Competing interests}

The authors declare that they have no competing interests.

\section{Author details}

${ }^{1}$ School of BioSciences, The University of Melbourne, Melbourne, Victoria 3010, Australia. ${ }^{2}$ Centre for Tropical Crops and Biocommodities, Institute for Future Environments, Queensland University of Technology, Brisbane, Queensland 4001, Australia. ${ }^{3}$ School of Agriculture, The University of Adelaide, Adelaide, South Australia 5064, Australia.

\section{Received: 15 August 2019 Accepted: 7 November 2019}

\section{Published online: 26 November 2019}

\section{References}

1. Foyer $\mathrm{CH}$, Noctor $\mathrm{G}$. Managing the cellular redox hub in photosynthetic organisms. Plant Cell Environ. 2012;35(2):199-201.

2. Foyer $\mathrm{CH}$, Shigeoka S. Understanding oxidative stress and antioxidant functions to enhance photosynthesis. Plant Physiol. 2011;155(1):93-100.

3. Foyer $\mathrm{CH}$, Noctor $\mathrm{G}$. Ascorbate and glutathione: the heart of the redox hub. Plant Physiol. 2011;155(1):2-18.

4. Lisko KA, Aboobucker SI, Torres R, Lorence A. Engineering elevated vitamin $C$ in plants to improve their nutritional content, growth, and tolerance to abiotic stress. In: Jetter R, editor. Phytochemicals-Biosynthesis, Function and Application. Switzerland: Springer; 2014. p. 109-28.

5. Macknight RC, Laing WA, Bulley SM, Broad RC, Johnson AA, Hellens RP. Increasing ascorbate levels in crops to enhance human nutrition and plant abiotic stress tolerance. Curr Opin Biotech. 2017;44:153-60.

6. De Tullio M, Arrigoni O. Hopes, disillusions and more hopes from vitamin C. Cell Mol Life Sci. 2004;61(2):209-19.

7. Debolt S, Melino V, Ford CM. Ascorbate as a biosynthetic precursor in plants. Ann Bot. 2006;99(1):3-8.

8. Potters G, De Gara L, Asard H, Horemans N. Ascorbate and glutathione: guardians of the cell cycle, partners in crime? Plant Physiol Biochem. 2002; 40(6-8):537-48.

9. Horemans N, Foyer $\mathrm{CH}$, Potters G, Asard H. Ascorbate function and associated transport systems in plants. Plant Physiol Biochem. 2000; 38(7-8):531-40.

10. Barth C, De Tullio M, Conklin PL. The role of ascorbic acid in the control of flowering time and the onset of senescence. J Exp Bot. 2006;57(8):1657-65.

11. Drouin G, Godin J-R, Pagé B. The genetics of vitamin C loss in vertebrates. Curr Genomics. 2011;12(5):371-8.

12. Lane DJ, Richardson DR. The active role of vitamin C in mammalian iron metabolism: much more than just enhanced iron absorption! Free Radic Biol Med. 2014;75:69-83.

13. Camarena V, Wang G. The epigenetic role of vitamin $C$ in health and disease. Cell Mol Life Sci. 2016;73(8):1645-58.

14. Troesch B, Hoeft B, McBurney M, Eggersdorfer M, Weber P. Dietary surveys indicate vitamin intakes below recommendations are common in representative Western countries. Br J Nutr. 2012;108(4):692-8.
15. Christie-David D, Gunton J. Vitamin C deficiency and diabetes mellituseasily missed? Diabet Med. 2017;34(2):294-6.

16. Dowdle J, Ishikawa T, Gatzek S, Rolinski S, Smirnoff N. Two genes in Arabidopsis thaliana encoding GDP-L-galactose phosphorylase are required for ascorbate biosynthesis and seedling viability. Plant J. 2007; 52(4):673-89.

17. Lim B, Smirnoff N, Cobbett CS, Golz JF. Ascorbate-deficient vtc2 mutants in Arabidopsis do not exhibit decreased growth. Front Plant Sci. 2016;7:1025.

18. Conklin PL, Saracco SA, Norris SR, Last RL. Identification of ascorbic aciddeficient Arabidopsis thaliana mutants. Genetics. 2000;154(2):847-56.

19. Baldet $P$, Bres $C$, Okabe $Y$, Mauxion J-P, Just $D$, Bournonville $C$, et al. Investigating the role of vitamin $C$ in tomato through TILLING identification of ascorbate-deficient tomato mutants. Plant Biotechnol. 2013:30(3):309-14.

20. Höller S, Ueda $Y$, Wu L, Wang Y, Hajirezaei M-R, Ghaffari M-R, et al. Ascorbate biosynthesis and its involvement in stress tolerance and plant development in rice (Oryza sativa L.). Plant Mol Biol. 2015;88(6):545-60.

21. Vidal-Meireles A, Neupert J, Zsigmond L, Rosado-Souza L, Kovács L, Nagy V, et al. Regulation of ascorbate biosynthesis in green algae has evolved to enable rapid stress-induced response via the VTC2 gene encoding GDP-Lgalactose phosphorylase. New Phytol. 2017;214(2):668-81.

22. Laing WA, Wright MA, Cooney J, Bulley SM. The missing step of the Lgalactose pathway of ascorbate biosynthesis in plants, an L-galactose guanyltransferase, increases leaf ascorbate content. Proc Natl Acad Sci U S A. 2007;104(22):9534-9.

23. Linster CL, Gomez TA, Christensen KC, Adler LN, Young BD, Brenner C, et al. Arabidopsis VTC2 encodes a GDP-L-galactose phosphorylase, the last unknown enzyme in the Smirnoff-wheeler pathway to ascorbic acid in plants. J Biol Chem. 2007;282(26):18879-85.

24. Bulley SM, Rassam M, Hoser D, Otto W, Schünemann N, Wright M, et al. Gene expression studies in kiwifruit and gene over-expression in Arabidopsis indicates that GDP-L-galactose guanyltransferase is a major control point of vitamin C biosynthesis. J Exp Bot. 2009:60(3):765-78.

25. Zhang G-Y, Liu R-R, Zhang C-Q, Tang K-X, Sun M-F, Yan G-H, et al. Manipulation of the rice L-galactose pathway: evaluation of the effects of transgene overexpression on ascorbate accumulation and abiotic stress tolerance. PLoS One. 2015;10(5):e0125870.

26. Zhou Y, Tao Q, Wang Z, Fan R, Li Y, Sun X, et al. Engineering ascorbic acid biosynthetic pathway in Arabidopsis leaves by single and double gene transformation. Biol Plantarum. 2012;56(3):451-7.

27. Bulley S, Laing W. The regulation of ascorbate biosynthesis. Curr Opin Plant Biol. 2016;33:15-22.

28. Bulley S, Wright M, Rommens $C$, Yan H, Rassam M, Lin-Wang K, et al. Enhancing ascorbate in fruits and tubers through over-expression of the Lgalactose pathway gene GDP-L-galactose phosphorylase. Plant Biotechnol J. 2012:10(4):390-7.

29. Li X, Ye J, Munir S, Yang T, Chen W, Liu G, et al. Biosynthetic gene pyramiding leads to ascorbate accumulation with enhanced oxidative stress tolerance in tomato. Int J Mol Sci. 2019;20(7):1558.

30. Wang L, Meng X, Yang D, Ma N, Wang G, Meng O. Overexpression of tomato GDP-L-galactose phosphorylase gene in tobacco improves tolerance to chilling stress. Plant Cell Rep. 2014:33(9):1441-51.

31. Ali B, Pantha S, Acharya R, Ueda Y, Wu L-B, Ashrafuzzaman M, et al. Enhanced ascorbate level improves multi-stress tolerance in a widely grown indica rice variety without compromising its agronomic characteristics. J Plant Physiol. 2019:40:152998.

32. Hellens RP, Brown CM, Chisnall MA, Waterhouse PM, Macknight RC. The emerging world of small ORFs. Trends Plant Sci. 2016;21(4):317-28.

33. Laing WA, Martínez-Sánchez M, Wright MA, Bulley SM, Brewster D, Dare AP, et al. An upstream open reading frame is essential for feedback regulation of ascorbate biosynthesis in Arabidopsis. Plant Cell. 2015;27(3):772-86.

34. Li T, Yang X, Yu Y, Si X, Zhai X, Zhang H, et al. Domestication of wild tomato is accelerated by genome editing. Nat Biotechnol. 2018;36:1160-3.

35. Zhang H, Si X, Ji X, Fan R, Liu J, Chen K, et al. Genome editing of upstream open reading frames enables translational control in plants. Nat Biotechnol. 2018;36:894-8.

36. Hayden CA, Jorgensen RA. Identification of novel conserved peptide uORF homology groups in Arabidopsis and rice reveals ancient eukaryotic origin of select groups and preferential association with transcription factorencoding genes. BMC Biol. 2007;5(1):32

37. Tran MK, Schultz CJ, Baumann U. Conserved upstream open reading frames in higher plants. BMC Genomics. 2008;9(1):361. 
38. Guerrero-González ML, Rodríguez-Kessler M, Jiménez-Bremont JF. UORF, a regulatory mechanism of the Arabidopsis polyamine oxidase 2. Mol Biol Rep. 2014;41(4):2427-43.

39. Hanfrey C, Elliott KA, Franceschetti M, Mayer MJ, Illingworth C, Michael AJ. A dual upstream open reading frame-based autoregulatory circuit controlling polyamine-responsive translation. J Biol Chem. 2005;280:39229-39237.

40. Hanfrey C, Franceschetti M, Mayer MJ, Illingworth C, Michael AJ. Abrogation of upstream open reading frame-mediated translational control of a plant S-adenosylmethionine decarboxylase results in polyamine disruption and growth perturbations. J Biol Chem. 2002;277:44131-44139.

41. Hu W-W, Gong H, Pua EC. The pivotal roles of the plant Sadenosylmethionine decarboxylase $5^{\prime}$ untranslated leader sequence in regulation of gene expression at the transcriptional and posttranscriptiona levels. Plant Physiol. 2005;138(1):276-86.

42. Kwak S-H, Lee SH. The regulation of ornithine decarboxylase gene expression by sucrose and small upstream open reading frame in tomato (Lycopersicon esculentum mill). Plant Cell Physiol. 2001;42(3):314-23.

43. Rahmani F, Hummel M, Schuurmans J, Wiese-Klinkenberg A, Smeekens S, Hanson J. Sucrose control of translation mediated by an upstream open reading frame-encoded peptide. Plant Physiol. 2009;150(3):1356-67.

44. Thalor SK, Berberich T, Lee SS, Yang SH, Zhu X, Imai R, et al. Deregulation of sucrose-controlled translation of a bZIP-type transcription factor results in sucrose accumulation in leaves. PLoS One. 2012;7(3):e33111.

45. Alatorre-Cobos F, Cruz-Ramírez A, Hayden CA, Pérez-Torres C-A, Chauvin A$L$, Ibarra-Laclette $E$, et al. Translational regulation of Arabidopsis XIPOTL1 is modulated by phosphocholine levels via the phylogenetically conserved upstream open reading frame 30. J Exp Bot. 2012;63(14):5203-21.

46. Zhu X, Li Y, Fang W, Kusano T. Galactinol is involved in sequence-conserved upstream open reading frame-mediated repression of Arabidopsis $\mathrm{HsfB} 1$ translation. Environ Exp Bot. 2018;156:120-9.

47. Sanahuja G, Farré G, Bassie L, Zhu C, Christou P, Capell T. Ascorbic acid synthesis and metabolism in maize are subject to complex and genotypedependent feedback regulation during endosperm development. Biotechnol J. 2013:8(10):1221-30.

48. IWGSC. Shifting the limits in wheat research and breeding through a fully annotated and anchored reference genome sequence. Science. 2018;361:661

49. Abhinandan K, Skori L, Stanic M, Hickerson NM, Jamshed M, Samuel MA. Abiotic stress signaling in wheat-an inclusive overview of hormonal interactions during abiotic stress responses in wheat. Front Plant Sci. 2018;9:734.

50. USDA Food Composition Databases. https://ndb.nal.usda.gov/ndb/.

51. Liu C, Atkinson M, Chinoy C, Devos K, Gale M. Nonhomoeologous translocations between group 4, 5 and 7 chromosomes within wheat and rye. Theor Appl Genet. 1992;83(3):305-12.

52. Akhunov ED, Sehgal S, Liang H, Wang S, Akhunova AR, Kaur G, et al. Comparative analysis of syntenic genes in grass genomes reveals accelerated rates of gene structure and coding sequence evolution in polyploid wheat. Plant Physiol. 2013;161(1):252-65.

53. Brenner C. Hint, Fhit, and GalT: function, structure, evolution, and mechanism of three branches of the histidine triad superfamily of nucleotide hydrolases and transferases. Biochemistry. 2002;41(29):9003-14.

54. Müller-Moulé P. An expression analysis of the ascorbate biosynthesis enzyme VTC2. Plant Mol Biol. 2008;68:31-41.

55. Wang L-Y, Li D, Deng Y-S, Lv W, Meng Q-W. Antisense-mediated depletion of tomato GDP-L-galactose phosphorylase increases susceptibility to chilling stress. J Plant Physiol. 2013;170(3):303-14.

56. Yang D-Y, Ma N-N, Zhuang K-Y, Zhu S-B, Liu Z-M, Yang X-H. Overexpression of tomato SIGGP-LIKE gene improves tobacco tolerance to methyl viologenmediated oxidative stress. J Plant Physiol. 2017;209:31-41.

57. Wicker T, Wing RA, Schubert I. Recurrent sequence exchange between homeologous grass chromosomes. Plant J. 2015;84(4):747-59.

58. Cerbin S, Jiang N. Duplication of host genes by transposable elements. Curr Opin Genet Dev. 2018;49:63-9.

59. Jiang N, Bao Z, Zhang X, Eddy SR, Wessler SR. Pack-MULE transposable elements mediate gene evolution in plants. Nature. 2004;431:569-79.

60. Hegde RR. Differential distribution of ascorbic acid and RNA in the developing anthers of Datura stramonium L. Bot Mag Tokyo. 1985; 98(3):219-23.

61. Kumar RR, Goswami S, Gadpayle KA, Singh K, Sharma SK, Singh G, et al. Ascorbic acid at pre-anthesis modulate the thermotolerance level of wheat
(Triticum aestivum) pollen under heat stress. J Plant Biochem Biot. 2014; 23(3):293-306.

62. Zhao D, Hamilton JP, Vaillancourt B, Zhang W, Eizenga GC, Cui Y, et al. The unique epigenetic features of pack-MULEs and their impact on chromosomal base composition and expression spectrum. Nucleic Acids Res. 2018;46(5):2380-97.

63. Asseng S, Ewert F, Martre P, Rötter RP, Lobell D, Cammarano D, et al. Rising temperatures reduce global wheat production. Nat Clim Chang. 2015:5:143-7.

64. Afzal I, Basra SM, Farooq M, Nawaz A. Alleviation of salinity stress in spring wheat by hormonal priming with ABA, salicylic acid and ascorbic acid. Int J Agric Biol. 2006;8(1):23-8.

65. Al-Hakimi A, Hamada A. Counteraction of salinity stress on wheat plants by grain soaking in ascorbic acid, thiamin or sodium salicylate. Biol Plantarum. 2001;44(2):253-61.

66. Athar H-u-R, Khan A, Ashraf M. Inducing salt tolerance in wheat by exogenously applied ascorbic acid through different modes. J Plant Nutr. 2009;32(11):1799-817.

67. Hafez E, Gharib H. Effect of exogenous application of ascorbic acid on physiological and biochemical characteristics of wheat under water stress. Int J Plant Prod. 2016;10(4):579-96.

68. Khan A, Ashraf M. Exogenously applied ascorbic acid alleviates salt-induced oxidative stress in wheat. Environ Exp Bot. 2008;63(1-3):224-31.

69. Malik S, Ashraf M. Exogenous application of ascorbic acid stimulates growth and photosynthesis of wheat (Triticum aestivum L.) under drought. Soil \& Environ. 2012;31(1).

70. Every D, Griffin W, Wilson P. Ascorbate oxidase, protein disulfide isomerase, ascorbic acid, dehydroascorbic acid and protein levels in developing wheat kernels and their relationship to protein disulfide bond formation. Cereal Chem. 2003:80(1):35-9.

71. Paradiso A, De Pinto M, Locato V, De Gara L. Galactone- $\gamma$-lactonedependent ascorbate biosynthesis alters wheat kernel maturation. Plant Biol. 2012;14(4):652-8.

72. De Gara L, De Pinto M, Arrigoni O. Ascorbate synthesis and ascorbate peroxidase activity during the early stage of wheat germination. Physiol Plant. 1997;100(4):894-900

73. Yang TK, Basu B, Ooraikul F. Studies on germination conditions and antioxidant contents of wheat grain. Int J Food Sci Nutr. 2001;52(4):319-30.

74. Kapustin Y, Souvorov A, Tatusova T, Lipman D. Splign: algorithms for computing spliced alignments with identification of paralogs. Biol Direct. 2008;3(1):20

75. Koressaar T, Remm M. Enhancements and modifications of primer design program Primer3. Bioinformatics. 2007;23(10):1289-91.

76. Untergasser A, Cutcutache I, Koressaar T, Ye J, Faircloth BC, Remm M, et al. Primer3-new capabilities and interfaces. Nucleic Acids Res. 2012; 40(15):e115.

77. Guindon S, Dufayard J-F, Lefort V, Anisimova M, Hordijk W, Gascuel O. New algorithms and methods to estimate maximum-likelihood phylogenies: assessing the performance of PhyML 3.0. Syst Biol. 2010;59(3):307-21.

78. Schreiber AW, Sutton T, Caldo RA, Kalashyan E, Lovell B, Mayo G, et al. Comparative transcriptomics in the Triticeae. BMC Genomics. 2009;10(1):285.

79. Beasley JT, Bonneau JP, Johnson AA. Characterisation of the nicotianamine aminotransferase and deoxymugineic acid synthase genes essential to Strategy II iron uptake in bread wheat (Triticum aestivum L.). PLoS One. 2017;12(5):e0177061.

80. Sears ER. The aneuploids of common wheat. Mo Agr Exp Sta Res Bull. 1954; 572:1-58.

81. Vandesompele J, De Preter K, Pattyn F, Poppe B, Van Roy N, De Paepe A, et al. Accurate normalization of real-time quantitative RT-PCR data by geometric averaging of multiple internal control genes. Genome Biol. 2002; 3(7):research0034

82. Ramírez-González R, Borrill P, Lang D, Harrington S, Brinton J, Venturini L, et al. The transcriptional landscape of polyploid wheat. Science. 2018;361:662.

83. Druka A, Muehlbauer G, Druka I, Caldo R, Baumann U, Rostoks N, et al. An atlas of gene expression from seed to seed through barley development. Funct Integr Genomics. 2006;6(3):202-11.

84. Sekhon RS, Lin H, Childs KL, Hansey CN, Buell CR, de Leon N, et al. Genomewide atlas of transcription during maize development. Plant J. 2011;66(4):553-63.

85. Davidson RM, Gowda M, Moghe G, Lin H, Vaillancourt B, Shiu SH, et al. Comparative transcriptomics of three Poaceae species reveals patterns of gene expression evolution. Plant J. 2012;71(3):492-502. 
86. Katoh K, Standley DM. MAFFT multiple sequence alignment software version 7: improvements in performance and usability. Mol Biol Evol. 2013; 30(4):772-80.

87. Curtis MD, Grossniklaus U. A gateway cloning vector set for highthroughput functional analysis of genes in planta. Plant Physiol. 2003; 133(2):462-9.

88. Lindbo JA. High-efficiency protein expression in plants from agroinfection-compatible tobacco mosaic virus expression vectors. BMC Biotechnol. 2007;7(1):52.

89. Bally J, Jung H, Mortimer C, Naim F, Philips JG, Hellens R, et al. The rise and rise of Nicotiana benthamiana: a plant for all reasons. Annu Rev Phytopathol. 2018:56:405-26.

90. Philips JG, Dudley KJ, Waterhouse PM, Hellens RP. The rapid methylation of T-DNAs upon Agrobacterium inoculation in plant leaves. Front Plant Sci. 2019;10:312.

91. Hellens RP, Edwards EA, Leyland NR, Bean S, Mullineaux PM. pGreen: a versatile and flexible binary Ti vector for Agrobacterium-mediated plant transformation. Plant Mol Biol. 2000;42(6):819-32.

92. Rassam M, Laing W. Variation in ascorbic acid and oxalate levels in the fruit of Actinidia chinensis tissues and genotypes. J Agric Food Chem. 2005;53(6):2322-6

\section{Publisher's Note}

Springer Nature remains neutral with regard to jurisdictional claims in published maps and institutional affiliations.

Ready to submit your research? Choose BMC and benefit from:

- fast, convenient online submission

- thorough peer review by experienced researchers in your field

- rapid publication on acceptance

- support for research data, including large and complex data types

- gold Open Access which fosters wider collaboration and increased citations

- maximum visibility for your research: over $100 \mathrm{M}$ website views per year

At BMC, research is always in progress.

Learn more biomedcentral.com/submissions 